Article

\title{
Feasibility and Surface Evaluation of the Pigment from Scytalidium cuboideum for Inkjet Printing on Textiles
}

\author{
Sarath M. Vega Gutierrez ${ }^{1, *}$, , Yujuan $\mathrm{He}^{2}{ }^{2}$ Yu Cao $^{2}$, Derek Stone ${ }^{2}$, Zielle Walsh ${ }^{3}$, \\ Rajiv Malhotra ${ }^{4}$, Hsiou-Lien Chen ${ }^{5}$, Chih-Hung Chang ${ }^{6}$ and Seri C. Robinson ${ }^{1}$ \\ 1 Department of Wood Science and Engineering, Oregon State University, Corvallis, OR 97331, USA; \\ seri.robinson@oregonstate.edu \\ 2 School of Chemical, Biological and Environmental Engineering, Oregon State University, Corvallis, OR 97331, \\ USA; heyuj@oregonstate.edu (Y.H.); caoyu@oregonstate.edu (Y.C.); stonede@oregonstate.edu (D.S.) \\ 3 Department of Integrative Biology, School of Life Sciences, Oregon State University, Corvallis, OR 97331, \\ USA; walshzi@oregonstate.edu \\ 4 Department of Mechanical and Aerospace Engineering, Rutgers University, 98 Brett Rd., Piscataway \\ Township, NJ 08854, USA; rajiv.malhotra@rutgers.edu \\ 5 College of Business, Oregon State University, Corvallis, OR 97331, USA; hsiou-lien.chen@oregonstate.edu \\ 6 Department of Chemical engineering, College of Science, Oregon State University, Corvallis, OR 97331, USA; \\ Chih-Hung.Chang@oregonstate.edu \\ * Correspondence: Sarath.vega@oregonstate.edu
}

Received: 28 February 2019; Accepted: 17 April 2019; Published: 19 April 2019

\begin{abstract}
Textile inkjet printing is an increasingly popular process in the textile industry, as it allows for the incorporation of complex and detailed patterns onto fabrics, as well as the production of small and medium volumes of printed text. Unfortunately, most of the dyes used by the textile industry come from synthetic and/or non-renewable sources. There has been some research to date in using fungal pigments from wood rotting fungi ('spalting' fungi) as textile dyes, however these have never been tested in inkjet printing. Of particular interest is the red crystallizing pigment from Scytalidium cuboideum, which has previously shown exceptional stability on textiles. To test this pigment in an inkjet setting, cotton and polyester fabrics were printed with three different ink formulations involving the red pigment: hexadecyltrimethylammonium bromide (CTAB), ethanol, and acetone. The CTAB and ethanol-based ink formulations formed a 'mesh-like' structure on the surface of the cotton and polyester fibers, and turned the fabric purple. Acetone formulas formed crystal structures on the surface and turned the fabric red. These results show promise for turning the red pigment of S. cuboideum into an environmentally friendly, inkjet colorant, however further research is required to evaluate the crocking and explain the crystallization differences between inks.
\end{abstract}

Keywords: inkjet textile printing; spalting; fungus crystals; textile dyeing

\section{Introduction}

Textile dyeing is an ancient practice, beginning sometime between $3000-400 \mathrm{BC}$, and is still one of the cores of the textile industry. Early dyes came mostly from natural sources, such as plants and mollusks, as well as minerals such as ochre and iron oxide [1,2]. But with an increased demand and a shift to mass production at the start of the 1700s, synthetic dyes became more popular and displaced the natural ones. This shift heralded increased research in synthetic dyes, which are still the base of the dye industry today [3].

Although synthetic dyes are relatively cheap and easy to mass produce, many come from non-renewable bases such as cadmium, titanium, iron, lead, etc. [4], which can be toxic for humans 
and wildlife, primarily through the wastewater effluents [5-7]. Wider consumer awareness about these hazards have encouraged research into natural pigments and dyes [8,9], particularly in the textile printing industry [10].

Before the mid 1700s, the techniques used for textile printing involved woodblocks, stencils, resistance dyeing, and silk printing (the last of which is still widely used) [3,4]. With an increased requirement for high volumes, these methods were replaced by roll printing. This method was developed by adapting paper roll printing to fit textiles, and it allowed the mass printing of textiles (around nine $\mathrm{km}$ of fabric per day per color) and is still in use. Roll printing has evolved since its conception, as currently is used for printing complex patterns in a wide array of colors. Its main advantage is also a limitation, as small or medium fabric volumes are not cost effective for roll printing [1,4].

For smaller and medium printing volumes, silk printing is widely used. But this technique has a limitation regarding the pattern detail (silk printing is effective for patterns with medium to low complexity) and number of colors that can be used [11,12]. A response to these limitations, was the development of digital textile inkjet printing (DTP) [13]. This method allows the direct printing of highly complex patterns directly onto fabrics. Inkjet printing on textiles was first attempted in 1970 in Zittau (former East Germany) [14], but found wider applications in the early 1980s by Seiren (Japan) [15]. This technology has evolved and is now currently used not only for printing patterns, but also to deliver other materials onto the textile. This specific characteristic has allowed for more research into types of inks (ranging from coloring to textile reinforcement), and options to more effectively deliver the inks [16].

Most of the currently used inks are based from synthetic pigments and dyes, and the DTP industry, like the dye industry, is looking for natural alternatives [17]. However most natural pigments and dyes require mordants and warm temperatures to fix the colors, and even after fixation, the colors have poor colorfastness and UV-light resistance [18].

Recent research into fungal pigments has shown that colorants extracted from spalting fungi (decay fungi that internally pigment wood) have great potential for use in textiles [19-21]. These pigments are of a naphthoquinonic nature [22-24] and have been observed to bind to a wide array of textiles (cellulosic, protein based and synthetic) when carried in dichloromethane (DCM) $[19,20]$. The use of these pigments is not recent, as they have been used since the early 1400s for fine woodworking [25-27]. The most well-known spalting fungi are from the genus Chlorociboria spp. This genus produces a characteristic blue-green pigmentation in wood (caused by xylindein, a secondary metabolite) [23,28-31], and the pigment can withstand UV-light [32]. Other spalting fungi with similar pigments and properties are Scytalidium cuboideum (Sacc. and Ellis) Sigler and Kang (ex. Arthrographis cuboidea) and Scytalidium ganodermophthorum Kang, Sigler, Lee and Yun (ex. Xylogone ganodermophthora). These fungi produce red and yellow coloration respectively [33-35]. Of special interest is the pigment from S. cuboideum, known as draconin red, as recent research has determined that the pigment is a naturally occurring crystal $[24,36]$. The crystal produced by this fungus is named 'Dramada' and is one of the few known naphthoquinonic crystals produced in nature. The pigment from S. ganodermophthorum is an as-of-yet unclassified compound.

The pigments from spalting fungi have been previously tested on textiles, using DCM and oils as carriers across two application methods: Immersion and dripping [19,20,37,38]. These previous studies showed that fungal pigments had high affinity with cotton (cellulosic) and polyester (synthetic), as well as resistance to crocking, UV-light, and laundry. Although the methods were successful, the use of $\mathrm{DCM}$ as a large-scale carrier for dyes is not practical for most industries. However, the pigment from S. cuboideum can be carried by a wide array of solvents (ethanol, acetone, acetonitrile, etc.), although slightly less effectively than in DCM [39]. These carriers make it possible to combine draconin red into different solutions and formulations that are more worker and industry friendly. The textile industry is currently developing further applications for digital textile inkjet printing (DTP). The application of spalting fungal pigments (especially the one from S. cuboideum), combined with DTP can increase 
the potential industrial applications for this outstanding group of fungal dyes, and offers the textile industry a much needed natural and renewable pigment with strong color stability.

This work focused on the surface of textiles printed with draconin red via an inkjet printer, and the evaluation of the dyeing with scanning electron microscopy (SEM). Two different textiles, polyester and cotton, as well as multiple solvent carriers, were assessed to determine which carriers and which textiles were best suited to the inkjet printing method. The importance of this study resides in evaluating the feasibility of the fungal pigment from S. cuboideum to be used as an ink component for textile inkjet printing, as well to determine if draconin red has potential for commercial use in the inkjet textile printing industry as a potential competitor for toxic, synthetic dyes.

\section{Materials and Methods}

\subsection{Pigment Production}

Cultures from Scytalidium cuboideum (UAMH 11517) were inoculated onto wood chip amended plates with $2 \%$ malt extract agar (MEA) (20 gr of malt with 15 gr of agar per liter) as discussed in Robinson et al. (2012) [40]. After the plates reached full pigmentation (4-6 weeks), they were left to dry overnight in a fume hood at room temperature. Each plate was then ground to approximately $2 \mathrm{~cm}$ particulate and then poured into a $250 \mathrm{~mL}$ Erlenmeyer flask. There, depending on the ink formulation, the pigment was extracted with the use of $30 \mathrm{~mL}$ of high performance liquid chromatography (HPLC) acetone (VWR, Brooklyn, NY, USA) or HPLC grade DCM (VWR, Brooklyn, NY, USA). Then, the solution was filtered with the use of a VWR 415 filter paper. Once extracted, the pigment was standardized to previously obtained CIELab values $\left(L^{*}=82.32, a^{*}=26.84, b^{*}=13.19\right)$ by Robinson et al. [41]. The CIELab values correspond to a $0.73 \mathrm{mM}$ concentration of pure 'Dramada', based on the relationship between molarity and color described by Vega Gutierrez et al. [36].

\subsection{Crystallization}

The crystallization method for the pigment was performed following the methods by Vega Gutierrez et al. (2018) [24]. The method consists of concentrating the pigment acetone extraction to a quarter of the original volume (if it was $1 \mathrm{~L}$ of standard acetone extract, this volume would be concentrated to a $250 \mathrm{~mL}$ volume). Then, the concentrated solution was flash frozen with the use of $100 \mathrm{~mL}$ of liquid nitrogen, which resulted in the surface of the acetone freezing. The cooled solution was then hand stirred for $30 \mathrm{~s}$ until a precipitate started to form at the bottom of the flask (the precipitate is of a maroon color). Then, the acetone solution and precipitate were filtered with the use of a VWR 415 filter paper. The precipitate was contained in the paper, and left to dry overnight to let the remaining acetone to evaporate. The precipitate crystals ('Dramada') were then collected from the filter paper with the use of forceps and stored in a $30 \mathrm{~mL}$ glass vial (ACE glass Inc., Vineland, NJ, USA).

\subsection{Textiles}

Two textiles were tested, cotton and polyester. The cotton fabric had a thread count density of 242 $(121 \times 121)$ with a weight of $131.59 \mathrm{~g} / \mathrm{m}^{2}$, and polyester had a thread count density of $163(83 \times 80)$ with a weight of $85.47 \mathrm{gr} / \mathrm{m}^{2}$. The fabrics were selected based upon their previous success rate with spalting fungal pigments in prior experiments with DCM carried pigments by Hinsch et al. (2015, 2016) $[20,37,38]$ and pigments carried in oils by Palomino Agurto et al. (2017) [21].

\subsection{Immersion}

The textiles were cut to $4 \mathrm{~cm} \times 4 \mathrm{~cm}$. Each textile was placed in a $200 \mathrm{~mL}$ Erlenmeyer flask with $100 \mathrm{~mL}$ of solubilized pigment (carried in acetone) for $15 \mathrm{~min}$. After the determined time passed, the textile pieces were left on a glass surface to dry overnight (ambient room temperature $20^{\circ} \mathrm{C}$ ) to allow complete evaporation of the solvent. Then, the textile samples were cut to $1 \mathrm{~cm} \times 1 \mathrm{~cm}$ and placed on a 
TED Pella Inc. (Redding, CA, USA) aluminum stud of once centimeter of diameter and affixed with TED Pella Inc. (Redding, CA, USA) double-coated carbon conductive tape.

\subsection{Dripping}

Textile sections of $4 \mathrm{~cm} \times 4 \mathrm{~cm}$ were placed on a flat glass surface, where 40 drops of pigment carried in acetone were applied using a VWR glass pipette. Each drop had an average volume of $0.0165 \mathrm{~mL}$, and after each application the acetone was allowed to evaporate. After finishing the 40-drop application the textiles were allowed to dry for $24 \mathrm{~h}$. Once the samples were completely dry, a center piece of $1 \mathrm{~cm} \times 1 \mathrm{~cm}$ was cut out and placed on a TED Pella Inc. (Redding, CA, USA) aluminum stud ( $1 \mathrm{~cm}$ diameter) and affixed with TED Pella Inc. (Redding, CA, USA) double-coated carbon conductive tape.

\subsection{Inkjet Printing}

Three different ink formulations were prepared for the test: hexadecyltrimethylammonium bromide (CTAB), ethanol, and acetone.

\subsubsection{CTAB-Based Ink}

The preparation of the inkjet-print ink contained 0.0364 gr of CTAB (Sigma-Aldrich, St. Louis, $\mathrm{MO}, \mathrm{USA})$ in $5 \mathrm{~mL}$ DCM solution of standardized pigment $(0.73 \mathrm{mM})$. Then, $1.5 \mathrm{~mL}$ water (deionized water) and $4.5 \mathrm{~mL}$ ethanol 200-proof (Pharmco-Aaper, Brookfield, CT, USA) were added. The mixture was stirred with a VWR CER hot/stir plate at $65^{\circ} \mathrm{C}$ for $4 \mathrm{~h}$. This process allowed the evaporation of DCM in the mixture, as measured by volume. The final ink was relatively stable and with printable viscosity and surface tension. Before jetted into the ink cartridge, the ink was filtered through a $0.45 \mu \mathrm{m}$ VWR $2 \mathrm{~mL}$ syringe filter.

\subsubsection{Ethanol-Based Ink}

The ethanol-based ink was prepared by dissolving 'Dramada' crystals into 90-proof ethanol (USP, North Bethesda, MD, USA, ACS grade) at a $0.73 \mathrm{mM}$ concentration. As the affinity of the crystals to ethanol is low, the solution required being placed into a sonicator (Kendal, China, HB-S-49MHT) for $8 \mathrm{~h}$ at $20^{\circ} \mathrm{C}$ and $42 \mathrm{KHz}$ of frequency to being fully dissolved. The ink was relatively stable in terms of printable viscosity and surface tension. Before jetting into the ink cartridge, the ink was filtered through a $0.45 \mu \mathrm{m}$ VWR $2 \mathrm{~mL}$ syringe filter. Although it is possible some dye may have adhered to the filter using this method, concentration was not remeasured, as the filter was used across all similar tests (so all similar concentrations would have had similar adherence).

\subsubsection{Acetone-Based Ink}

'Dramada' crystals were dissolved in acetone to obtain a $0.73 \mathrm{mM}$ solution. To completely dissolve the crystals, the mixture of acetone and crystals was placed on a VWR CER hot/stir plate at $200 \mathrm{rpm}$ for ten minutes. Before jetted into the ink cartridge, the ink was filtered by a $0.45 \mu \mathrm{m}$ VWR $2 \mathrm{~mL}$ syringe filter.

\subsection{Inkjet Printing}

A FujiFilm Dimatix inkjet printer (Santa Clara, CA, USA) was utilized for printing the ink onto different fabrics (cotton and polyester) in a $2.54 \mathrm{~cm}$ by $2.54 \mathrm{~cm}$ pattern. The drop spacing was set as $5 \mu \mathrm{m}$, which provided the maximum drop amounts in one print-cycle. The temperatures of both print head and fabric holder were maintained at room temperature. For each sample, four print-cycles were applied. Controls were prepared in a similar manner on $2 \mathrm{~cm}$ glass squares with a square pattern of $1 \mathrm{~cm}$ by $1 \mathrm{~cm}$. In Figure 1, the printed square pattern can be observed on cotton. 


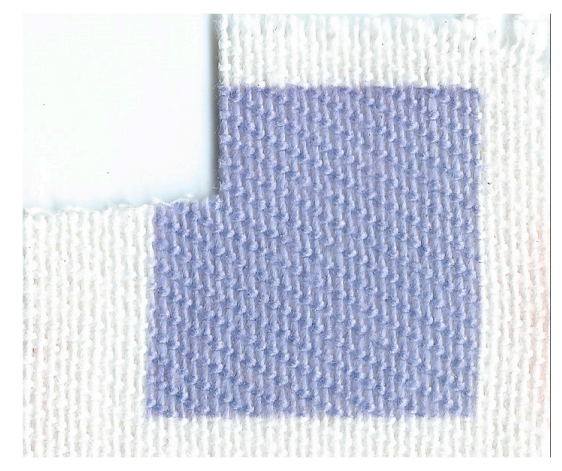

Figure 1. Square pattern printed with CTAB-based ink, on cotton.

\subsection{Image Scanning}

Color images of the fabric samples were obtained by scanning them at a 1200 dpi resolution using an Epson Perfection V370 Photo Scanner (Epson, Nagano Prefecture, Japan).

\subsection{Scanning Electron Microscopy (SEM)}

SEM samples were coated with a gold-palladium $(\mathrm{Au}-\mathrm{Pb})$ sputter for $35 \mathrm{~s}$ (resulting coating of 30-45 nm) using a Cressington Sputter Coater 108 Auto (Cressington Scientific instruments Inc., Cranberry Twp, PA, USA). The sputter allowed an enhanced optical contrast on all the samples as it prevented electron charging of the sample.

For the image analysis, two different microscopes were used. The FEI QUANTA 600F environmental SEM (FEI Co., Hillsboro, OR, USA) was used for images up to $20 \mu \mathrm{m}$, but a higher resolution was required for further detail imaging on the textile fibers. To do that, a FEI Helios NanoLab DualBeam (FEI Co., Hillsboro, OR, USA) was used as the images obtained with it had a higher resolution and could reach a higher magnification $(10-5 \mu \mathrm{m})$ without distortion.

\section{Results}

\subsection{Textile Controls}

Images of the textiles controls can be observed in Figure 2a,b. Cotton fibers showed a rougher and irregular surface (a combination of rugged and smooth surfaces) in comparison to polyester. Polyester was the fabric that had the most smooth surface and a slight angular shape on its fibers (it is possible to observe a few imperfections on its fiber surface).

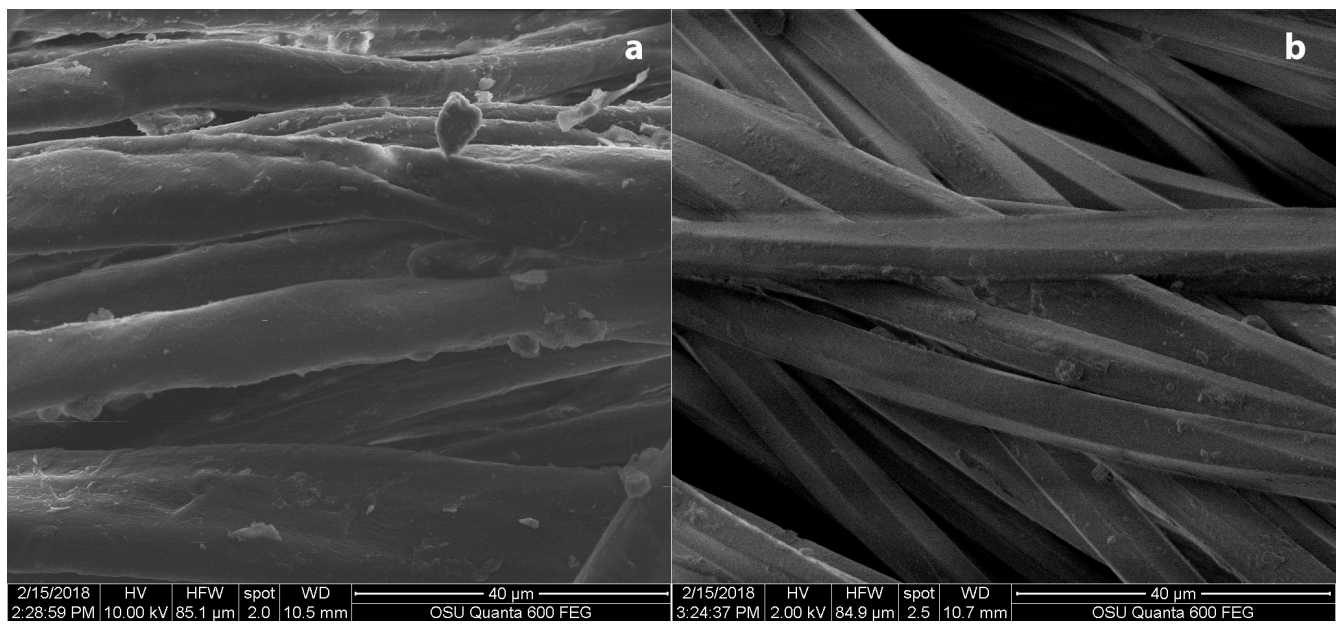

Figure 2. Undyed controls for (a) cotton; (b) polyester, showing differences in surface texture. Images taken with a FEI Quanta 600. 


\subsection{Dripping and Immersion}

Figure 3 shows the different colorations obtained by the dripping and immersion treatments on cotton and polyester. For the dripping method for cotton with both solvent-carriers (Figure 3a,b), it is possible to observe a pigment accumulation on the surface of the yarns. These accumulations are a result of the evaporation of the solvents. A similar effect is observed on polyester with dripped acetone-based ink (Figure 3e), where a higher pigment concentration is visible near the edges of the fabric (the edges were formed due to the sample wrapped edges during the treatment application). The same treatment but with the ethanol-based ink on polyester (Figure 2f) shows a color variation (from red hues with acetone, to purple-blue hues with ethanol) which can also be seen on cotton (Figure $3 \mathrm{a}, \mathrm{b}$ ). The immersion treatment for both fabrics and solvent-carriers (Figure 3c,d,h) showed lighter hues when compared to the dripping test. On Figure $3 g$ is possible to observe the accumulation of pigment near the fabric edge, which is caused by the evaporation movement of the solvent.

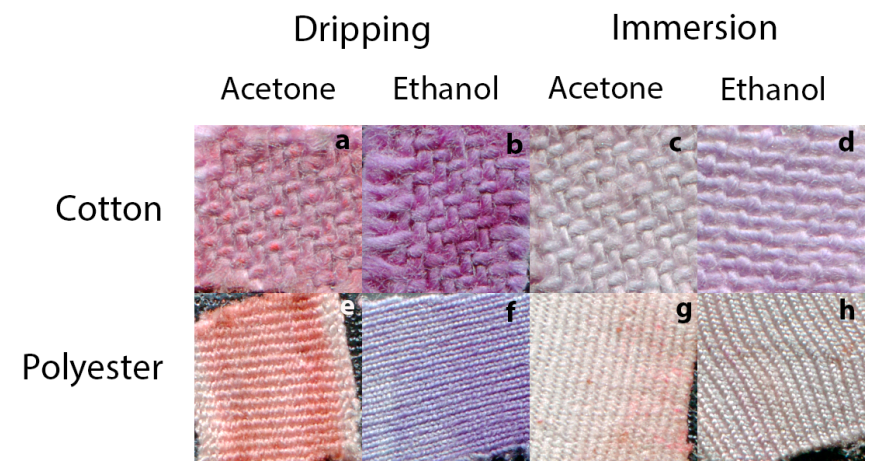

Figure 3. Swatches of dyed fabrics, showing the color change from the dramada pigment across fabric and solvent: (a) acetone dye on cotton, applied through dripping; (b) ethanol dye on cotton applied through dripping; (c) acetone dye on cotton applied through immersion; (d) ethanol dye on cotton applied through immersion; (e) acetone dye on polyester applied through dripping; (f) ethanol dye on polyester applied through dripping; (g) acetone dye on polyester applied through immersion; (h) ethanol dye on polyester applied through immersion.

\subsubsection{Cotton}

Dripping (Figure 4a) and immersion (Figure $4 \mathrm{~b}$ ) treatments with ethanol showed similar surface details to cotton. Both treatments resulted in needle-like crystalline structures (from S. cuboideum) on the surface of the cotton fibers. The average size of the formed crystals was between 3-5 $\mu \mathrm{m}$ in length and 0.2 to $0.3 \mu \mathrm{m}$ in thickness. Besides the crystal size, it was possible to observe crystals scattered across the fibers.

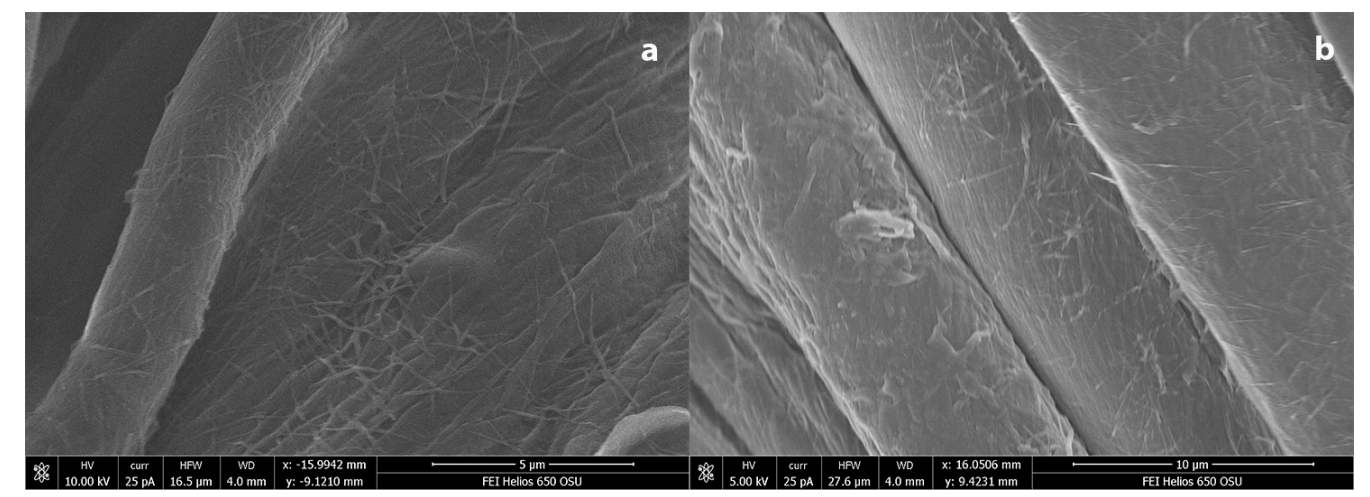

Figure 4. Results from the dripping and immersion testing, showing needle-like crystals on (a) Cotton treated with dripped ethanol-based ink, focused on a single fiber; (b) Immersion ethanol based-ink treatment on cotton, showing crystallization on several fibers. Images taken with a FEI Helios 650. 


\subsubsection{Polyester}

The surface of polyester differed between those dipped in the solution and those dyed via immersion, with ethanol as the carrier. In Figure 5a, the dripping treatment formed a complex agglomerate of flattened crystals on the polyester fiber surface. Meanwhile, the immersion treatment (Figure 5b) showed a crystal distribution similar to the one observed on cotton with the same treatment.

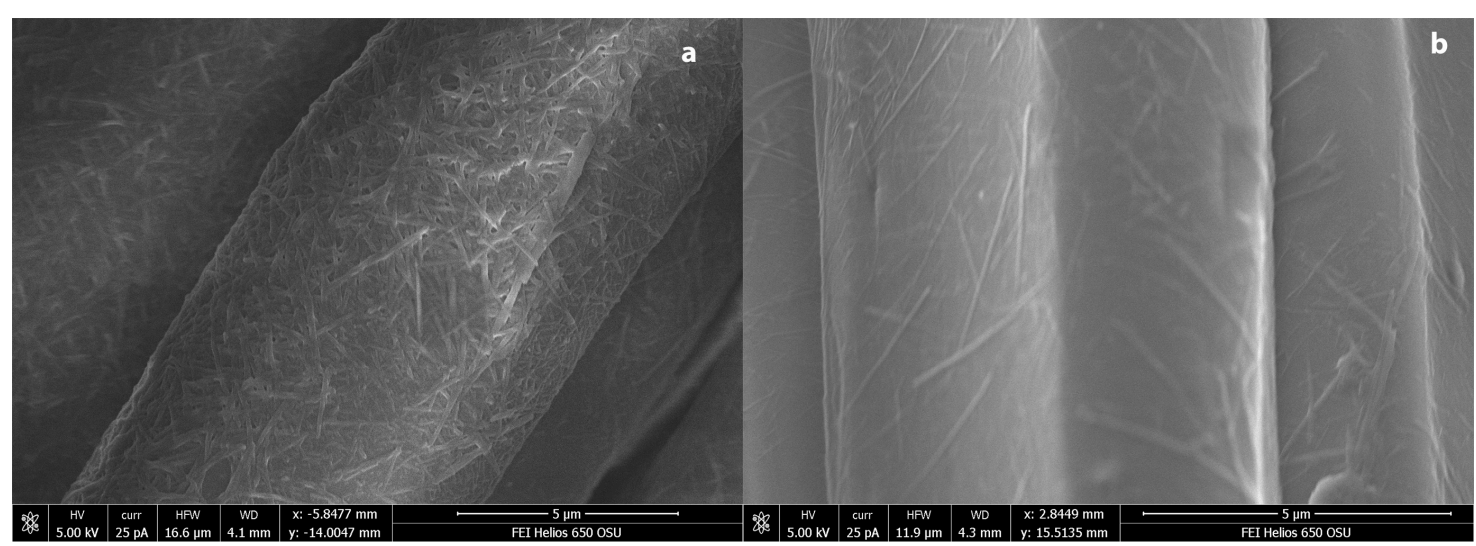

Figure 5. Surface of polyester fibers after dyeing via two different methods: (a) Ethanol-based ink dripping on polyester; (b) Ethanol-based ink immersion on polyester. Images taken with a FEI Helios 650 .

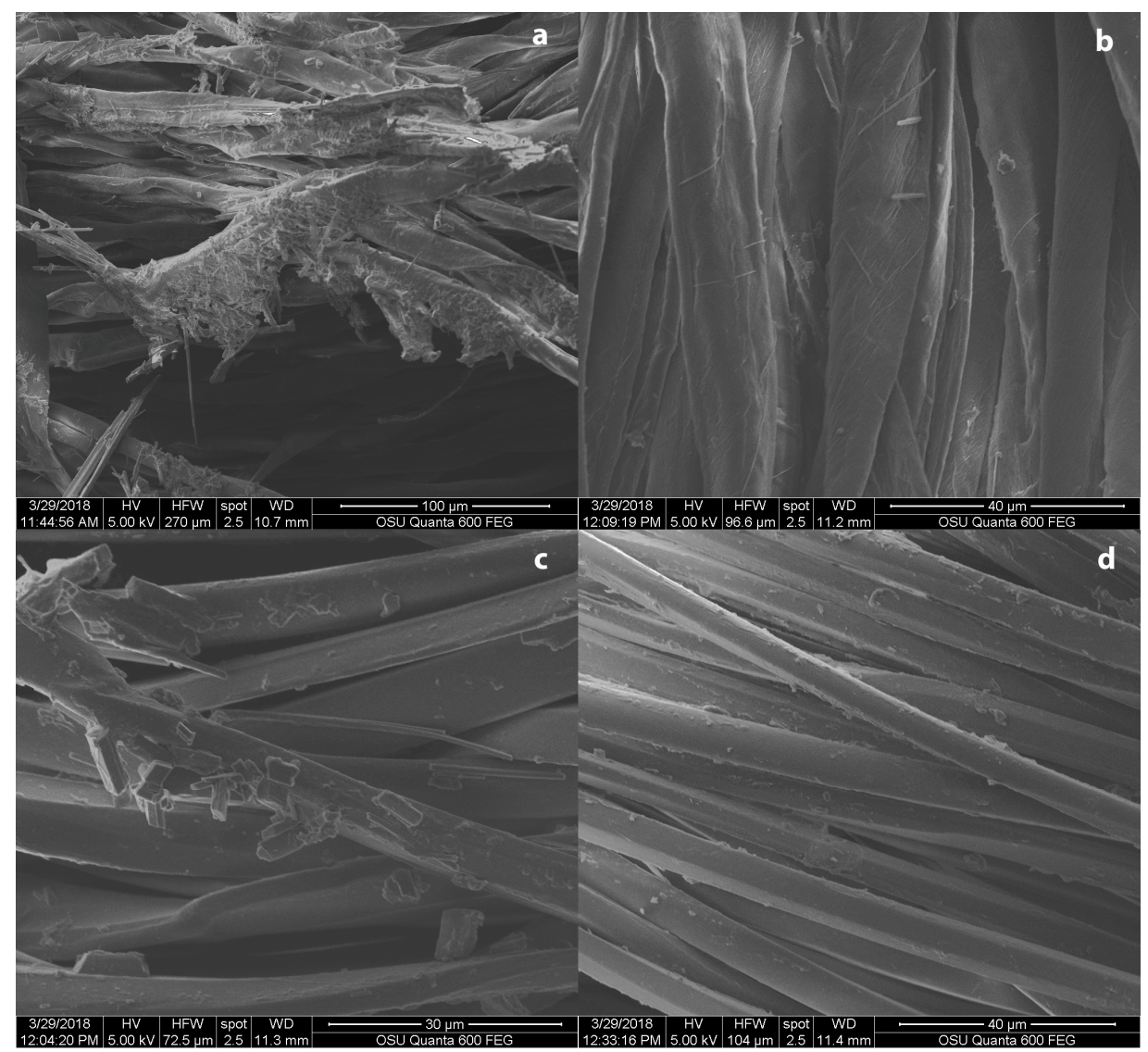

Figure 6. Dripping test results across several fabrics, with acetone: (a) Acetone-based ink dripping showing crystal clusters (pointed with a red arrow); (b) immersion on cotton fibers; (c) Acetone-based ink dripping and (d) immersion on polyester fibers. Crystallization is generally larger in acetone than ethanol, hence the change in micron size. Images taken with a FEI Quanta 600. 
The dripping test with acetone on cotton showed clusters of crystals accumulating at the ends of the fibers (Figure 6a). Interestingly, the crystal formation between dripping and immersion were visually different. For immersion, the crystals carried in acetone had a highly scattered distribution on the fiber (Figure $6 \mathrm{~b}$ ), and did not form clusters as with the dripping treatment. In comparison to cotton, dripping and immersion treatments with acetone had similar results to polyester (Figure $6 c, d$ ). On polyester, 'Dramada' formed rectangular structures that were thicker and shorter when compared to the structures formed when carried in ethanol, that were more needle-like. Also, the distribution of the acetone carried crystals was scattered along the fibers on both treatments (dripping and immersion), showing no visual difference between the applications.

\subsection{Printing: $\mathrm{CTAB}, \mathrm{EtOH}$ and Acetone}

\subsubsection{Controls}

The printed controls were applied on a glass surface. Each ink (CTAB, ethanol, and acetone) showed different patterns. CTAB-based ink (Figure 7a) showed amorphous and flattened structures on the glass. The ethanol-based ink (Figure $7 \mathrm{~b}$ ), showed bigger amorphous structures as well as scattered needle-like structures on the glass. Acetone-based ink (Figure 7c) showed the highest difference when compared to $\mathrm{CTAB}$ and ethanol. The pigmented ink with acetone showed the formation of crystals with sizes over $20 \mu \mathrm{m}$.

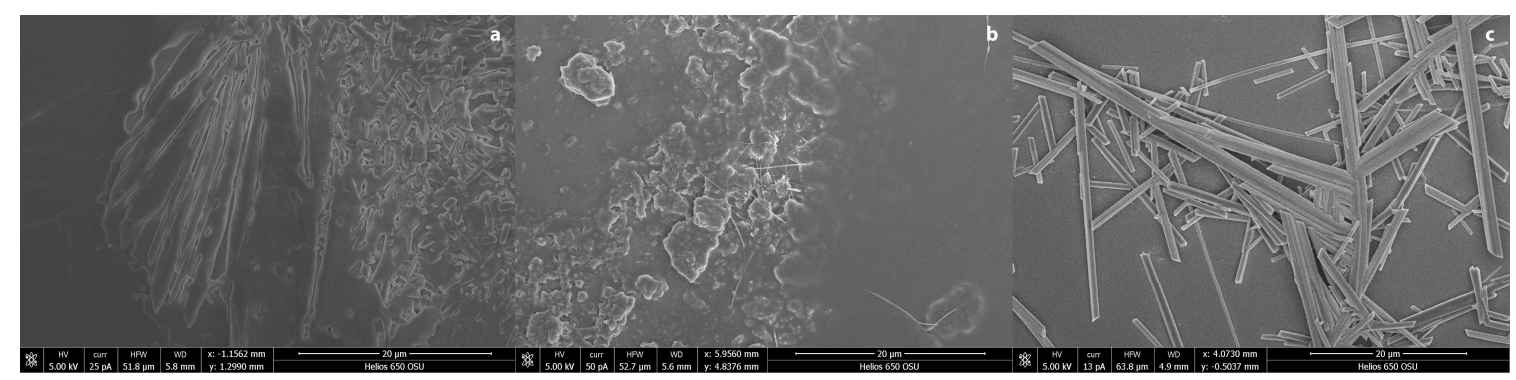

Figure 7. Printed glass with (a) CTAB-based ink; (b) ethanol-based ink; and (c) acetone-based ink. Images taken with a FEI Helios 650.

\subsubsection{Cotton and Polyester}

Figure $8 \mathrm{a}$,e show the textile controls for polyester and cotton. Figure $8 \mathrm{~b}$ shows the printed surface of polyester with the CTAB formulation, the coloration obtained corresponded to a pale red-purple color. In Figure 8c the ethanol-based ink printed surface polyester shows a similar shade as the CTAB-based ink, but with a more intense pigmentation. Figure $6 \mathrm{~d}$ shows polyester printed with the acetone-based ink, on that figure it is possible to observe a red shade with higher intensity, when compared to the other inks. For cotton, the CTAB- and ethanol-based inks (Figure 8f,g respectively) show pigmentation on purple hues, with the ethanol-based ink showing a more intense hue. In Figure $8 \mathrm{~h}$ the cotton fabric printed with acetone shows a lighter coloration that tends to red hues. Not only the visual difference was apparent, but the surface analysis also showed differences.

Cotton printed with CTAB-based ink showed a mesh-like structure with the needle-like structures formed by the pigment (Figure 9a). These structures covered the whole surface of the cotton fibers. A detail of the printed surface (Figure $9 \mathrm{~b}$ ) shows that the structures formed have a morphology similar to the ones observed with the ethanol dripping treatment $(3-5 \mu \mathrm{m}$ in length and 0.2 to $0.3 \mu \mathrm{m}$ of thickness). 


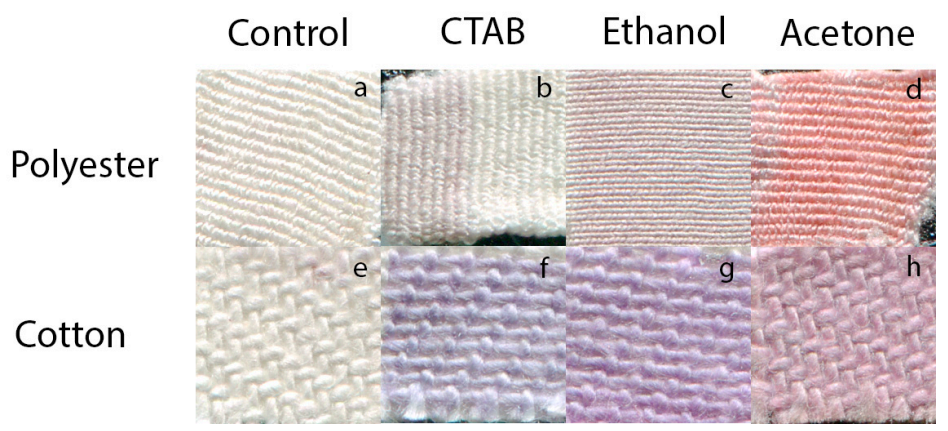

Figure 8. Printed fibers, including controls, showing color change in the dramada pigment. (a) Unprinted polyester; (b) Polyester printed with CTAB-based ink (pointed to by the purple arrow); (c) Polyester printed with ethanol-based ink; (d) Polyester printed with acetone-based ink; (e) Unprinted cotton; (f) Cotton printed with CTAB-based ink; (g) Cotton printed with ethanol-based ink; (h) Cotton printed with acetone-based ink.

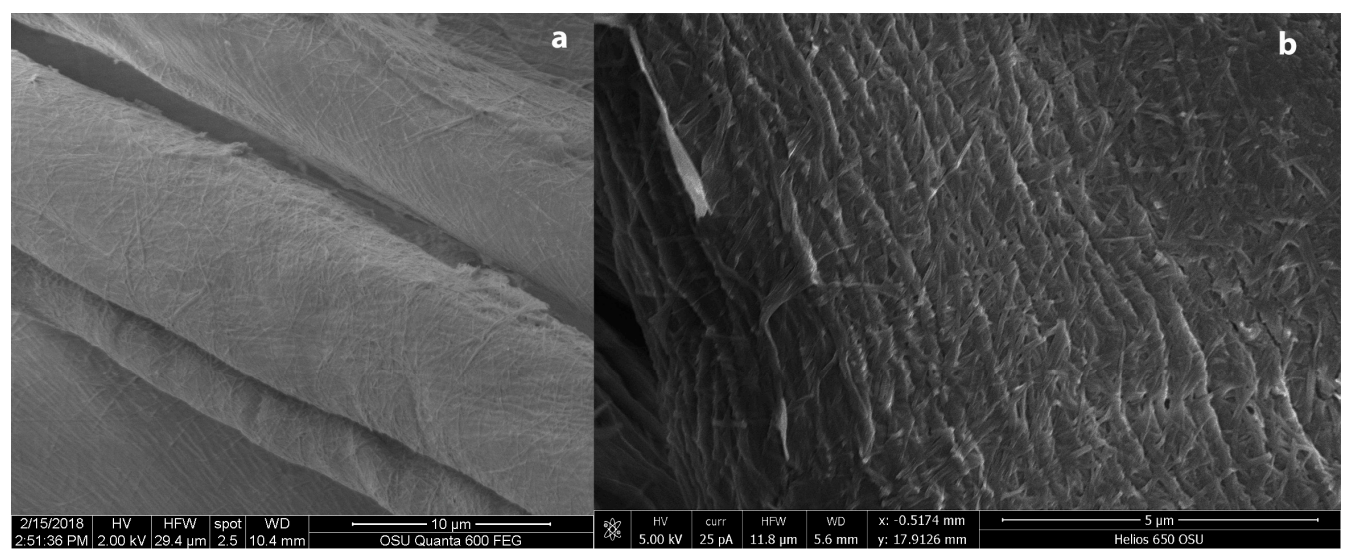

Figure 9. (a) Cotton printed CTAB-based ink, image taken with a FEI Quanta 600; (b) Detail of the surface of the CTAB-based ink printed cotton surface. Image taken with a FEI Helios 650.

The ethanol-based ink coating was not obvious on cotton at a magnification $20 \mu \mathrm{m}$ (Figure 10a), but it was distinguishable at $4 \mu \mathrm{m}$ (Figure 10b). On the last figure, it is possible to see that the structures formed by the pigment of $S$. cuboideum were of a reduced size (shorter than $2 \mu \mathrm{m}$ ) when compared against CTAB and acetone.

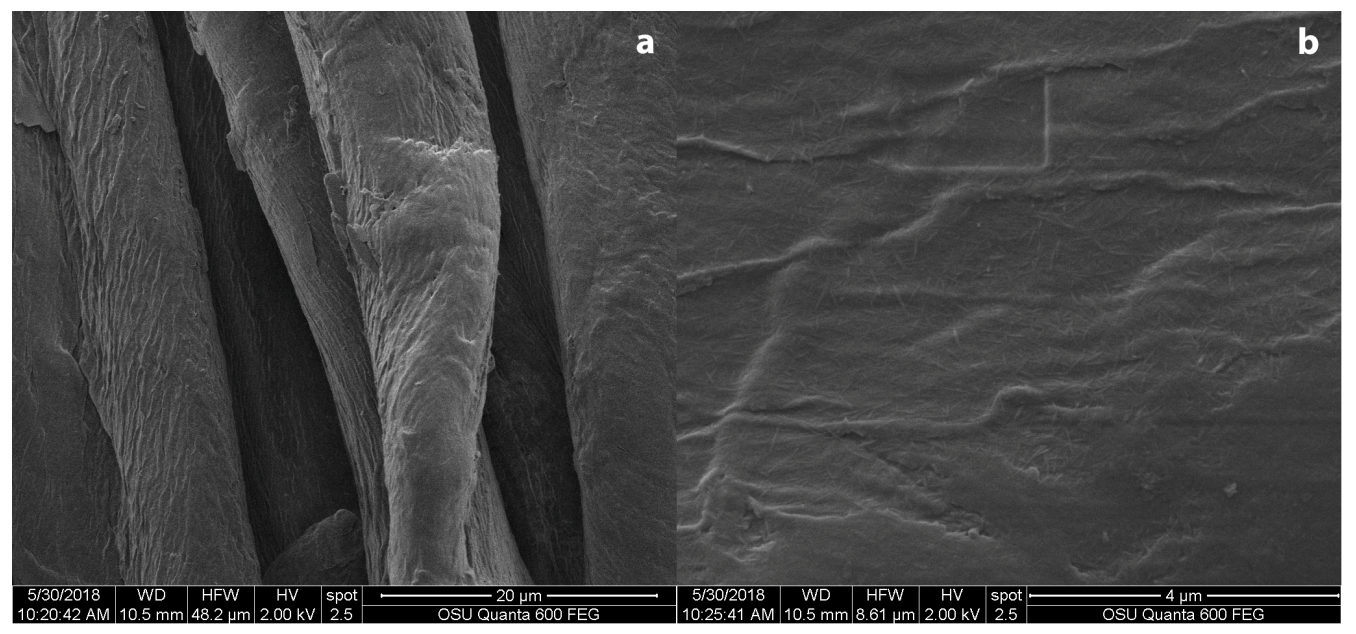

Figure 10. (a) Cotton printed with ethanol-based ink, image taken with a FEI Quanta 600; (b) Magnification of the printed surface. Image taken with a FEI Helios 650. 
Polyester printed with CTAB (Figure 11a) showed a similar 'mesh-like' pattern as cotton with the same ink (Figure 9a). The crystal structures were bigger and more discernable at a $5 \mu \mathrm{m}$ magnification. The ethanol-based ink formed an irregular surface on the polyester fiber (Figure 11b), as well as irregularly shaped crystals on the sides.

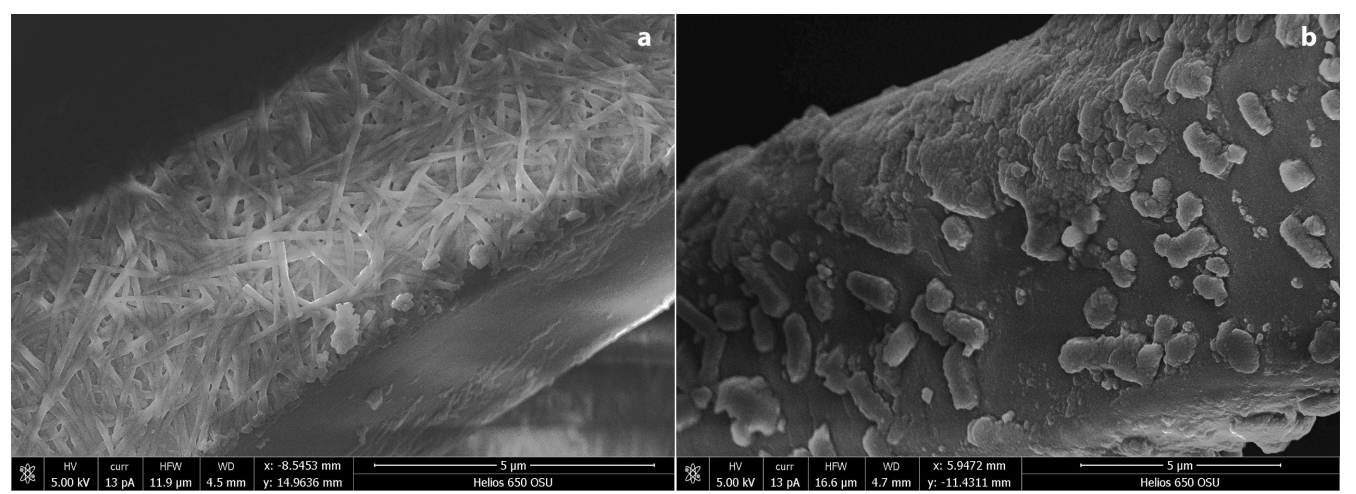

Figure 11. (a) Polyester printed with CTAB; (b) Polyester printed with ethanol. Images taken with a FEI Helios 650.

\subsection{Printing: Acetone}

Acetone-based ink had different interactions with cotton (Figure 12a) and polyester (Figure 12b). On cotton, the ink showed sparse crystal structures, but it did not form the 'mesh-like' structures that were previously observed with the CTAB on cotton (Figure 9a) and polyester (Figure 11a). The 'Dramada' crystals on cotton had an average length of 10 and $0.1 \mu \mathrm{m}$ in width. In contrast, the acetone-based ink in polyester had thicker and shorter crystals (five $\mu \mathrm{m}$ of length and a width of $0.2-0.4 \mu \mathrm{m}$ ), with a similar appearance as the immersion acetone treatment (Figure $6 \mathrm{~d}$ ).

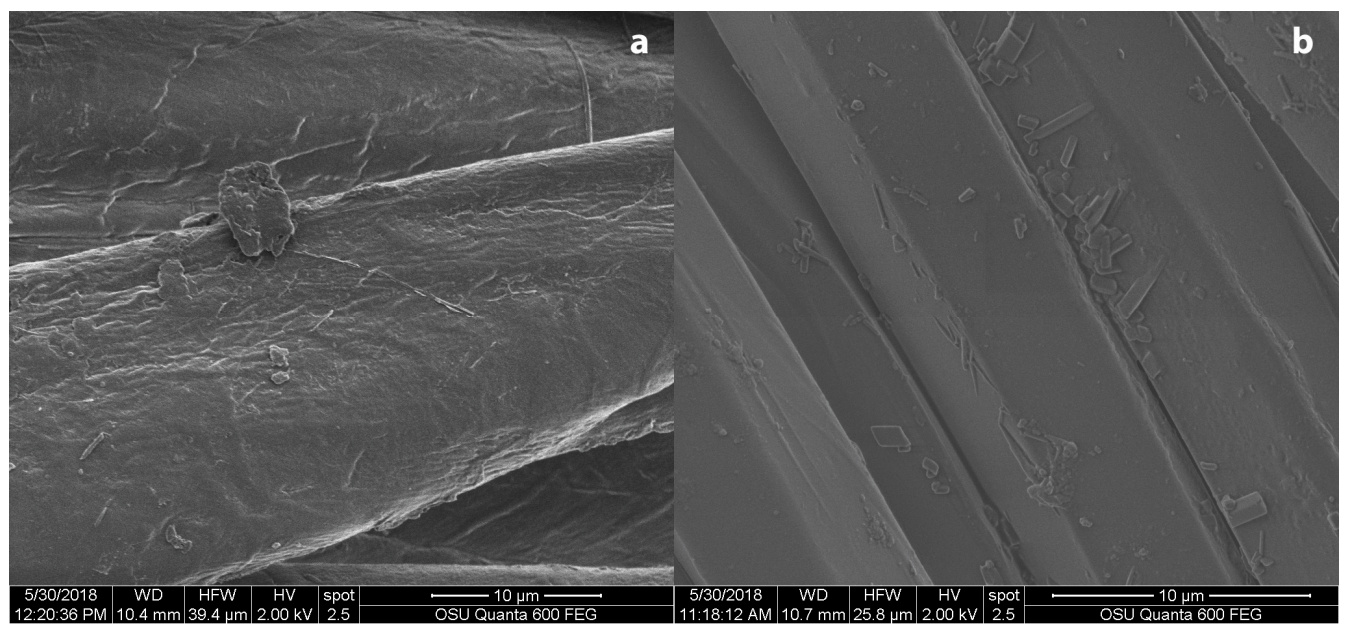

Figure 12. (a) Cotton printed with acetone-based ink; (b) Polyester printed with acetone-based ink. Images taken with a FEI Quanta 600.

\section{Discussion}

\subsection{Dripping and Immersion}

The results obtained with dripping and immersion treatments with ethanol and acetone showed differences between the carriers and textiles. On cotton, both treatments with ethanol presented a dispersion of crystals across the cotton fibers. When compared against a previous study that used DCM instead [42], the DCM did not achieve an even distribution of crystals (as was observed with 
ethanol and acetone in this study), due to a migration of the pigments to the ends of the textile fibers. A possible explanation for this phenomenon can be attributed to the different evaporation rates of DCM, acetone, and ethanol. As DCM has a faster evaporation and a higher density $(1.326 \mathrm{~g} / \mathrm{mL})$ [43] than ethanol $(0.789 \mathrm{~g} / \mathrm{mL})$, is possible that it is affected by the capillarity of cotton at a higher degree than the ethanol. Another difference is within the crystal size. The interaction of the 'Dramada' crystals when carried by ethanol, and deposited on cotton, resulted in crystals $3-5 \mu \mathrm{m}$ in length and 0.2 to $0.3 \mu \mathrm{m}$ in thickness, in comparison with previous results of the crystals carried in DCM that were 0.95-47 $\mu \mathrm{m}$ in length and 2-4 $\mu \mathrm{m}$ in thickness [42]. Also, from these tests, it was possible to observe the color variation between the solvents and fabrics.

The interaction of acetone with cotton with dripping showed a similar behavior as the one reported for cotton with DCM. Both solvents with dripping tended to have crystal agglomerations at the ends of the fibers. In contrast, the immersion treatment of cotton with acetone showed a behavior similar to ethanol (dispersed crystals along the fibers). This result may be due to the similar densities of acetone $(0.788 \mathrm{~g} / \mathrm{mL})$ and ethanol $(0.789 \mathrm{~g} / \mathrm{mL})$. These observations from SEM are also relatable to the color obtained. The dripping treatments in general resulted in more vivid colors (which can relate to a greater amount of pigments deposited on the fabric surface), while the immersion treatments resulted in paler colors (with more dispersed crystals on the fiber surfaces). These results show that immersion treatments tend to deposit fewer quantities of pigments compared to the dripping test. Correlating this to the ink-jet printing methods where the pigments are deposited in a micro-dripping manner, it is possible to assert that the obtained colors are going to be more intense, if compared to batch-dyeing methods (fabric immersion).

For polyester, both treatments (dripping and immersion) and solvents (ethanol and acetone) showed dissimilar results. The combination of polyester with ethanol dripping showed the formation of a 'mesh-like' crystal structure, while the immersion treatment had similar results to ethanol (dispersed crystals along the fiber). The formation of the 'mesh-like' structure has not been previously observed with DCM, where needle-like crystals were observed on the fabric surfaces [24,42].

A different interaction was observed with the crystals carried in acetone and polyester. Both treatments showed the formation of well-defined rectangular crystalline structures, as well as a coloration that tended to red hues. This morphology has been previously observed on the crystallized form of the pure pigment [24,36], and differs of what has been previously observed in DCM [42], where the crystals showed a flattened structure that 'wrapped' around the polyester fiber. It is possible that effects like evaporation rate and solvent density play an important role in the formation of the crystalline structures, as well as interactions with the fabric surface. As different textile fibers have different physical properties - of which capillarity is the most likely to influence absorption rate and pigment distribution - cotton is known to have higher capillarity than polyester [44]. As each of the treatments (solvents and delivery methods) showed visual differences in how the 'Dramada' crystals interacted with the fabrics, more research is required in the chemical and physical field to be able to explain the different morphologies observed within each of them.

\subsection{Printing: CTAB, Ethanol, and Acetone}

The three ink formulations studied showed different 'Dramada' crystal configurations when printed on glass. CTAB and ethanol-based formulations showed amorphous structures, whilst acetone showed well-defined crystal structures. These changes in morphology require further chemical research, as the crystalline structures have also been observed with DCM [42], but this is the first time reporting an amorphous configuration on controls, although these configurations changed when the pigment was applied to fabrics. It is important to note here that the CTAB-based ink dried in a similar time as the ethanol and acetone (droplet size was small). Therefore, no differences were noted around evaporation time.

It is also important to mention that previous experimentation on the analysis of the pigments has shown that the crystals shown are not artifacts produced by the imaging, as an extensive study of 
these pigments has been previously performed by Vega Gutierrez et al. (2017) [42]. On that study it was also observed that the crystals are produced only by S. cuboideum, as other pigments from fungi have a porous configuration. Additional studies focusing on potential solvents carrying S. cuboideum have also been performed, and the crystallization was observed on samples with the pigments and not on the controls [45].

The CTAB-based ink formulation on cotton and polyester showed similar 'mesh-like' structures, as well as a coloration that tended to purple hues. Cotton with the ethanol-based ink also had this structure but with a different crystal size. Ethanol-based ink on polyester formed structures that were between amorphous to rectangular shaped, as well as a paler coloration. Similar to the dripping and immersion tests, these structures have not been reported before and further testing is required to determine the interaction between the pigment from S. cuboideum and the solvent carriers. When the SEM images were compared to the resulting printing colorations, it was possible to infer that there exists a correlation between crystal morphology and resulting color. The mesh-like structures that were observed on the CTAB and ethanol-based inks resulted in colors that tended to the purple-hues on cotton and polyester, while the more angular-shaped crystals produced by the acetone-based ink resulted in red hues. This relation requires further research, as it is possible that is affected not only by the solvent-carrier, but also by the printing cycles and textile interactions. Interestingly, it was observed that the printed ink stayed mostly on the surface of the textile. This could prove problematic for commercialization, as most current textile inks absorb into the fibers [46], and having the colorant sit on the surface is likely to affect its color stability.

Such absorption is usually achieved with the use of nanoparticles to deliver the inks internally, as well as to avoid obstructions of the printing nozzle [17,47]. One of the advantages of delivering the ink internally to the fiber is increased colorfastness (although mordants can also help in this area). This last topic is also one of the most studied ones, as there is a current development of different mechanisms such as UV-curable inks [48], chitosan [49], and textile surface pretreatments [17,46,50] that have the sole goal to increase the color fastness of the inks. In the case of textile surface pretreatments, there have been several studies related to improving the capacity of silk, linen, polyester, and cotton [51-53] to absorb and bind pigments more efficiently on their surface. Also, there is ongoing research into adding mordants [54] and other components [55,56] in the ink, to make the fabric more 'receptive' to the colorant [18].

\subsection{Fungal Pigments-Breaking the Rules}

However, previous research into the pigmenting capabilities of S. cuboideum has shown that textiles like polyester show remarkable colorfastness without the need of mordants or pretreatments [20,38]. This pigment has also shown a degree of versatility with their affinity to a wide array of carriers, such as the ones tested for the ink formulations, as well as natural oils [21]. All of these characteristics show that $S$. cuboideum red pigment has the potential to be used as a natural dye for textile inkjet printing. As the current market continues to press into more renewable sources for dyes, colorants from nature, such as carmine (pigment from Dactylopius coccus) [57], annatto (Bixa Orellana), cutch (Acacia catechu), and golden dock (Rumex maritimus) [58], will become increasingly important. The ability to make inks that do not contain salts is also beneficial, as salts can affect the printing nozzle [18] by creating blockages. Spalting fungal pigments may be the answer to natural colorants that do not require heat nor mordents to adhere, yet are nontoxic, colorfast, and light resistant-a boon for the industrial textile industry. To complete the development of draconin red for such a future, further testing into the ink formulations, crystallization, textile interactions, crocking and colorfastness is required.

\section{Conclusions}

The different applications (dripping, immersion, and printing), textiles, and ink formulations showed different morphologies for the 'Dramada' crystals of S. cuboideum. Printed textiles with CTAB and ethanol formulations tended to form 'mesh-like' structures covering the surface of the textile (cotton 
and polyester) fibers, accompanied by a visual purple hue, while acetone-based formulations formed well-shaped crystal structures as well as red coloration. Overall, fungal pigments from Scytalidium cuboideum showed promising results as a potential ink component for textile printing.

Author Contributions: Conceptualization, Y.H. and Y.C.; Data Curation, S.V.G., Y.H., Y.C., D.S. and Z.W.; Formal Analysis, S.V.G.; Funding Acquisition, R.M., H.-L.C., C.-H.C. and S.R.; Investigation, S.V.G., Y.H. and Y.C.; Methodology, S.V.G., Y.C., R.M., H.-L.C., C.-H.C. and S.R.; Resources, Y.H., R.M., H.-L.C., C.-H.C. and S.R.; Visualization, S.V.G.; Writing—original draft, S.V.G.; Writing—Review and Editing, S.R.

Funding: This research was funded by the Walmart Manufacturing Innovation Fund.

Acknowledgments: The authors gratefully acknowledge Oregon State University Electron Microscopy facilities, Peter Eschbach, and Teresa Sawyer.

Conflicts of Interest: The authors declare no conflict of interest.

\section{References}

1. Schoeser, M. World Textiles, a Concise History, 1st ed.; Thames \& Hudson Ltd: New York, NY, USA, $2003 ;$ p. 224.

2. Ferreira, E.S.; Hulme, A.N.; McNab, H.; Quye, A. The natural constituents of historical textile dyes. Chem. Soc. Rev. 2004, 33, 329-336. [CrossRef]

3. Robinson, S. A History of Dyed Textiles, 1st ed.; Studio Vista Limited: London, UK, 1969; p. 112.

4. Miles, L.W.C. Textile Priting, 1st ed.; Merrow Publishing Co. Ltd.: London, UK, 1971; p. 46.

5. Pointing, S. Feasibility of bioremediation by white-rot fungi. Appl. Microbiol. Biotechnol. 2001, 57, 20-33. [PubMed]

6. Kant, R. Textile dyeing industry an environmental hazard. Nat. Sci. 2012, 4, 22-26. [CrossRef]

7. Nilsson, I.; Möller, A.; Mattiasson, B.; Rubindamayugi, M.; Welander, U. Decolorization of synthetic and real textile wastewater by the use of white-rot fungi. Enzym. Microb. Technol. 2006, 38, 94-100. [CrossRef]

8. Zaffalon, V. Climate change, carbon mitigation and textiles. Text. World 2010, 160, 34-35.

9. Mussak, R.A.M.; Bechtold, T. Natural colorants in textile dyeing. In Handbook of Natural Colorants; John Wiley \& Sons, Ltd.: Hoboken, NJ, USA, 2009; pp. 315-337.

10. Poorniammal, R.; Parthiban, M.; Gunasekaran, S.; Murugesan, R.; Thilagavathi, G. Natural dye production from Thermomyces sp. Fungi for textile application. Indian J. Fibre Text. Res. 2013, 38, 276-279.

11. Samanta, A.K.; Agarwal, P. Application of natural dyes on textiles. Indian J. Fibre Text. Res. 2009, 34, 384-399.

12. Samanta, A.K.; Konar, A. Dyeing of textiles with natural dyes. In Natural Dyes, 1st ed.; Kumbasar, D.E.A., Ed.; InTech: Rijeka, Croatia, 2011; pp. 29-56.

13. Gupta, S. Inkjet printing-a revolutionary ecofriendly technique for textile printing. Indian J. Fibre Text. Res. 2001, 26, 156-161.

14. Kulube, C. Colour generation in textile ink-jet printing. S. Afr. J. Sci. 1998, 94, 469-472.

15. Ujiie, H.X. Digital Printing of Textiles; Woodhead Publishing: Sawston, UK, 2006.

16. Cie, C. Ink-Jet Textile Printing, 1st ed.; Woodhead Publishing Limited: Sawston, UK, 2015; p. 183.

17. Kan, C.W.; Yuen, C.W.M. Digital ink-jet printing on textiles. Res. J. Text. Appar. 2012, 16, 1-24. [CrossRef]

18. Fryberg, M. Dyes for ink-jet printing. Rev. Prog. Coloration Relat. Top. 2005, 35, 1-30. [CrossRef]

19. Weber, G.; Chen, H.-L.; Hinsch, E.; Freitas, S.; Robinson, S. Pigments extracted from the wood-staining fungi Chlorociboria aeruginosa, Scytalidium cuboideum, and S. ganodermophthorum show potential for use as textile dyes. Coloration Technol. 2014, 130, 445-452. [CrossRef]

20. Hinsch, E.M.; Weber, G.; Chen, H.-L.; Robinson, S.C. Colorfastness of extracted wood-staining fungal pigments on fabrics: A new potential for textile dyes. J. Text. Appar. Technol. Manag. 2015, 9.

21. Palomino Agurto, M.E.; Vega Gutierrez, S.M.; Chen, H.-L.; Robinson, S.C. Wood-rotting fungal pigments as colorant coatings on oil-based textile dyes. Coatings 2017, 7, 152. [CrossRef]

22. Edwards, R.L.; Kale, N. The structure of xylindein. Tetrahedron 1965, 21, 2095-2107. [CrossRef]

23. Saikawa, Y.; Watanabe, T.; Hashimoto, K.; Nakata, A. Absolute configuration and tautomeric structure of xylindein, a blue-green pigment of Chlorociboria species. Phytochemistry 2000, 55, 237-240. [CrossRef]

24. Vega Gutierrez, S.M.; Hazell, K.K.; Simonsen, J.; Robinson, S.C. Description of a naphthoquinonic crystal produced by the fungus Scytalidium cuboideum. Molecules 2018, 23, 1905. [CrossRef] 
25. Otterstedt, A. Investigating green marquetry on bowed-string instruments. The leaves be Greene. Galpin Soc. J. 2001, 54, 330-338. [CrossRef]

26. Michaelsen, H.; Unger, A.; Fischer, C.-H. Blaugrüne färbung an intarsienhölzern des 16. Bis 18. Jahrhunderts. Restauro 1992, 98, 17-25.

27. Blanchette, R.A.; Wilmering, A.M.; Baumeister, M. The use of green-stained wood caused by the fungus Chlorociboria in intarsia masterpieces from the 15th century. Holzforschung 1992, 46, 225-232. [CrossRef]

28. Blackburn, G.M.; Ekong, D.E.; Nielson, A.H.; Todd, L. Xylindein. Chimia 1965, 19, $208-212$.

29. Giles, R.G.F.; Reuben, M.K.; Roos, G.H.P. A quinonoid napthtopyranone as a model for the synthesis of the pigment xylindeine. Photochemical formation of the lactone ring. S. Afr. J. Chem. 1979, 32, 127-129.

30. Giles, R.G.F.; Green, I.R.; Hugo, V.I. Model studies towards xylindein precursors. S. Afr. J. Chem. 1990, 48, 28-33.

31. Maeda, M.; Yamauchi, T.; Oshima, K.; Shimomura, M.; Miyauchi, S.; Mukae, K.; Sakaki, T.; Shibata, M.; Wakamatsu, K. Extraction of xylindein from Chlorociboria aeruginosa complex and its biological characteristics. Bull. Nagaoka Univ. Technol. 2003, 25, 105-111.

32. Beck, H.G.; Freitas, S.; Weber, G.; Robinson, S.C.; Morrell, J.J. Resistance of Fungal Derived Pigments to Ultraviolet Light Exposure; IRG/WP, Ed.; International Research Group in Wood Protection: St George, UT, USA, 2014.

33. Robinson, S.C.; Tudor, D.; Zhang, W.R.; Ng, S.; Cooper, P.A. Ability of three yellow pigment producing fungi to colour wood under controlled conditions. Int. Wood Prod. J. 2014, 5, 103-107. [CrossRef]

34. Kang, H.; Sigler, L.; Lee, J.; Gibas, C.; Yun, S.; Lee, Y. Xylogone ganodermophthora sp. nov., an ascomycetous pathogen causing yellow rot on cultivated mushroom Ganoderma lucidum in Korea. Mycologia 2010, 102, 1167-1184. [CrossRef] [PubMed]

35. Robinson, S.C.; Tudor, D.; Cooper, P.A. Utilizing pigment-producing fungi to add commercial value to american beech (Fagus grandifolia). Appl. Microbiol. Biotechnol. 2012, 93, 1041-1048. [CrossRef]

36. Vega Gutierrez, S.; Van Court, R.C.; Stone, D.; Konkler, M.; Groth, E.; Robinson, S. Relationship between molarity and color in the crystal ('dramada') produced by Scytalidium cuboideum, in two solvents. Molecules 2018, 23, 2581. [CrossRef]

37. Hinsch, E.M. A Comparative Analysis of Extracted Fungal Pigments and Commercially Available Dyes for Colorizing Textiles. Master's Thesis, Oregon State University, Corvallis, OR, USA, 2015.

38. Hinsch, E.M.; Robinson, S.C. Mechanical color reading of wood-staining fungal pigment textile dyes: An alternative method for determining colorfastness. Coatings 2016, 6, 25. [CrossRef]

39. Pittis, L.; Rodrigues de Oliveira, D.; Vega Gutierrez, S.M.; Robinson, S.C. Alternative carrier solvents for pigments extracted from spalting fungi. Materials 2018, 11, 897. [CrossRef] [PubMed]

40. Robinson, S.C.; Tudor, D.; Snider, H.; Cooper, P.A. Stimulating growth and xylindein production of Chlorociboria aeruginascens in agar-based systems. AMB Express 2012, 2,1-7. [CrossRef]

41. Robinson, S.C.; Weber, G.; Hinsch, E.; Vega Gutierrez, S.M.; Pittis, L.; Freitas, S. Utilizing extracted fungal pigments for wood spalting: A comparison of induced fungal pigmentation to fungal dyeing. J. Coat. 2014, 2014, 1-8. [CrossRef]

42. Vega Gutierrez, S.M.; Robinson, S.C. Microscopic analysis of pigments extracted from spalting fungi. J. Fungi 2017, 3, 15. [CrossRef]

43. Young, J.A. Dichloromethane. J. Chem. Educ. 2004, 81, 1415. [CrossRef]

44. Almoughni, H.; Gong, H. Capillary flow of liquid water through yarns: A theoretical model. Text. Res. J. 2015, 85, 722-732. [CrossRef]

45. Palomino Agurto, M.E. Wood-Rotting Fungal Pigments as Colorant Coatings on Oil-Based Textile Dyes: A Detailed View of The Interaction Between Fungal Pigments and Some Commercial Fabrics. Master's Thesis, Oregon State University, Corvallis, OR, USA, 2018.

46. Leelajariyakul, S.; Noguchi, H.; Kiatkamjornwong, S. Surface-modified and micro-encapsulated pigmented inks for ink jet printing on textile fabrics. Prog. Org. Coat. 2008, 62, 145-161. [CrossRef]

47. Xue, C.-H.; Shi, M.-M.; Chen, H.-Z.; Wu, G.; Wang, M. Preparation and application of nanoscale microemulsion as binder for fabric inkjet printing. Colloids Surf. A Physicochem. Eng. Asp. 2006, 287, 147-152. [CrossRef]

48. Hakeim, O.A.; Arafa, A.A.; Zahran, M.K.; Abdou, L.A.W. Characterisation and application of pigmented uv-curable inkjet inks. Pigment Resin Technol. 2018, 47, 164-172. [CrossRef]

49. Yuen, C.W.M.; Ku, S.K.A.; Kan, C.W.; Choi, P.S.R. Enhancing textile ink-jet printing with chitosan. Coloration Technol. 2007, 123, 267-270. [CrossRef] 
50. El-Hennawi, H.M.; Shahin, A.A.; Rekaby, M.; Ragheb, A.A. Ink-jet printing of bio-treated linen, polyester fabrics and their blend. Carbohydr. Polym. 2015, 118, 235-241. [CrossRef] [PubMed]

51. Soleimani-Gorgani, A.; Karami, Z. The effect of biodegradable organic acids on the improvement of cotton ink-jet printing and antibacterial activity. Fibers Polym. 2016, 17, 512-520. [CrossRef]

52. Zhao, C.; Wang, C.; Chen, K.; Yin, Y. Improvement of ink-jet printing performances using $\beta$-cyclodextrin forming inclusion complex on cotton fabric. Fibers Polym. 2017, 18, 619-624. [CrossRef]

53. Leva, M.; Gherasimescu, C.; Butnaru, R. Study regarding the ink-jet printing with reactive dyes of natural silk. The influence of pretreatment conditions on the intensity of the prints. Ind. Text. 2011, 62, 151-154.

54. Wataoka, I. Ink-jet printing using natural dyes. Sen-I Gakkaishi 2012, 68, 176-179. [CrossRef]

55. Yang, Y.; Li, S. Cotton fabric inkjet printing with acid dyes. Text. Res. J. 2003, 73, 809-814. [CrossRef]

56. Karanikas, E.K.; Nikolaidis, N.F.; Tsatsaroni, E.G. Synthesis, characterization, and application of hetarylazo disperse colorants: Preparation and properties of ink-jet inks with active agents for polyester printing. J. Appl. Polym. Sci. 2012, 125, 3396-3403. [CrossRef]

57. Xue, Y.; Wang, X. Influencing factors of carmine ink jet printing effect on silk fabric. Text. Aux. 2017, 34, 46-49. (In Chinese)

58. Savvidis, G.; Karanikas, E.; Nikolaidis, N.; Eleftheriadis, I.; Tsatsaroni, E. Ink-jet printing of cotton with natural dyes. Coloration Technol. 2014, 130, 200-204. [CrossRef]

(C) 2019 by the authors. Licensee MDPI, Basel, Switzerland. This article is an open access article distributed under the terms and conditions of the Creative Commons Attribution (CC BY) license (http://creativecommons.org/licenses/by/4.0/). 